\title{
The Analysis of the Media Convergence Ecosystem Value Chain based on Broadcast and Communications Media Convergence Technology
}

\author{
Chi-Ung Song ${ }^{1}$ and Mi-Young Park ${ }^{2}$ \\ ${ }^{1}$ Science and Technology Policy Institute \\ ${ }^{2}$ Seoul Women's University \\ cusong ${ }^{1} @$ stepi.re.kr, ollive $e^{2} @ s w u . a c . k r$
}

\begin{abstract}
Broadcasting and communications industries with traditional value chains, such as live performances, music, event planning, broadcasting, movies, publishing, and advertising, operate under planning, production, distribution, and consumption stages and have witnessed the fusion of planning and production, the simultaneous occurrence of production and distribution, and the convergence of producers and consumers, resulting in changes in the traditional value chain structure. This suggests a need for policymakers to examine these changes in the context of the ecosystem value chain and reconsider their goals to set appropriate human resources targets. This paper analyzes the importance of economic and scientific aspects of the impact media convergence has had on society, discerns the reason for changes in the value chain of broadcasting and communications industries from a multiphase and linear structure to a convergent value chain structure, and presents some suggestions for future policies on broadcast and communications media convergence technologies.
\end{abstract}

Keywords: Creative Domestic Industries, Value Chain of the Broadcasting and Communications Industries, Media Convergence, Media Convergence Policy, Media Convergence Value Chain, Broadcast and Communications Media Convergence Technologies, Ecosystem Value Chain

\section{Introduction}

The fusion of broadcast and communications technologies based on broadcasting \& communication technology infrastructure and Changes in business participants mentioned earlier has produced a new business model in the 2000s. Lieberman [4] defines the core economic elements of creative industries through the 4Cs: 1) content (products supplied to consumers), 2) conduct (methods through which products are passed on), 3) consumption (consumers' relationships with products), and 4) convergence (what fuses content and technologies into new forms). Particularly clear in Lieberman's 4C convergence stage are changes in the convergence platform business.

In recent years, the convergent platform business has scrutinized the business ecosystem based on the value chain of content, platforms, networks, and terminals (CPNT value chain). The most important advantage of the CPNT value chain is that it reflects the convergence of technologies that enable one-source multi-use (OSMU) applications [5]. The convergence of technologies that appropriately transform media content from one source into many different kinds of media has extended the life cycle of content by enabling it to be used in many different ways in planning, production, and distribution stages of the value chain. In addition, 
because reproducing content creates high value added with less investment, it is seen as a type of knowledge-intensive industry with the potential to be a core engine for countries wishing to become the most advanced developed nations in the twenty-first century [6-9] what makes such content production possible is the convergence of broadcast and communications technologies. Convergent technologies can be summarized as media convergence expression, information-processing, content, content and information security, and transmission and linkage technologies. These technologies are responsible for considerable economic growth from their job creation and cultural impacts. However, the development of these technologies relies on the country's capital and national technology management policy [10-12]. A fundamental problem concerning this issue is that defining media convergence technologies is not easy because it is difficult to determine where media convergence boundaries are at the industry level as wired and wireless communications, voice data, and broadcast content, among others, converge with the IT infrastructure [13]. In other words, it is difficult to define boundaries of consumers and places of transactions in which competitive relationships are established through interactions between firms and consumers. However, if the market is not defined first, then media convergence technologies, which require large capital, are likely to take on monopolistic exclusivity, and M\&A activities are likely to occur, concentrating the market share in certain firms. In addition, combining traditional media may create unforeseen legal problems that are difficult to control. Therefore, the necessary technological development for content production must have a guiding policy based on an established technology aim supported by the government.

Broadcast and communications media convergence technologies represent particularly important software-centric service technologies crucial for creative industries. In this regard, they have higher value add and a greater impact on job creation than hardware technologies $[9,11,14-17]$. These technologies have substantial impacts not only in economic areas but also in cultural ones and thus can enhance the global image of a country as well as its citizens' quality of life. In this regard, the government's active support for creative industries and policy initiatives for technologies that these industries depend on can be important strategies for the growth of future industries. This paper examines the most recent broadcast and communications media convergence technologies and provides an AHP analysis based on in-depth interviews and surveys targeting experts in terms of what economic and scientific/technological importance future technology projects may have in advancing domestic media convergence. More specifically, structural characteristics of various areas of cultural content in creative industries, including broadcasting/drama, film, and music industries, are examined through their economic ecosystems for their roles in determining the status of domestic broadcast and communication media convergence technologies and predicting changes in their future demand. The results have important implications for science and technology policies.

\section{Evolution of the Broadcast and Communications Media Convergence Value Chain}

\subsection{Concept and Elements of Broadcast and Communications Media Convergence}

Broadcast and communications firms have been reestablishing the planning, production, distribution, and consumption flow of content based on the convergence of broadcast and communications technologies. As shown in Figure 1, these firms have realized technological and economic profits through the CPNT value chain, in which content is moved to a platform, distributed through a network, and passed on to consumers through terminal devices [13]. 


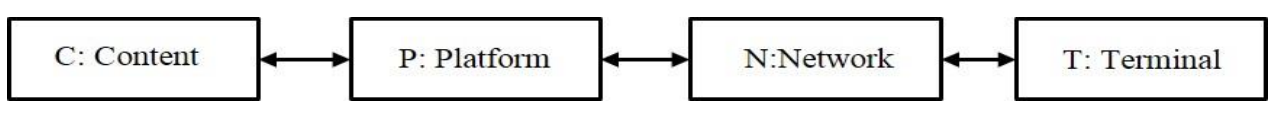

Figure 1. CPNT Value Chain

The most notable aspect of this new value chain is how the planning, production, and processing of content are divided according to the technology necessary for each level. Platform technologies refer to various media sources such as 1) multichannel-based broadcasting, 2) the widespread use of clip content, 3) the widespread use of individual media based on bilateral communication, and 4) the supply of realistic media. Developments in media convergence content can go so far as to decide the rate of development in hardware and software technologies. In addition, in the case of digital content, the same content can be consumed by different digital devices, extending the life cycle of content based on the nearzero reproduction cost and enhancing the value add of content in convergent media. The last stage "terminal" refers to the variety of consumption devices that confer the advantage of not only an individual being able to send content to various devices over a network but also users using these devices to create their own content to send to other devices. Therefore, each stage of the value chain generates an interaction in which it is not the difference between stages but their linkage that is emphasized. Content is composed of broadcast and communications content and defined as media convergence content. Broadcast content is defined as "all content for broadcast media," and communications content, as "all content distributed over communications networks" [19]. Figure 3 presents the convergence of the traditional content production process and the new technology-centered content production process and shows the broadcast and communications infrastructure technologies that form the basis of the convergent value chain (content creation, network technologies, services and platforms, and device environments) in Table 1. The figure also shows how changes in business participants are included in the CPNT value chain stages and how they (a fusion of producers and proactive consumers) are central to the convergence.

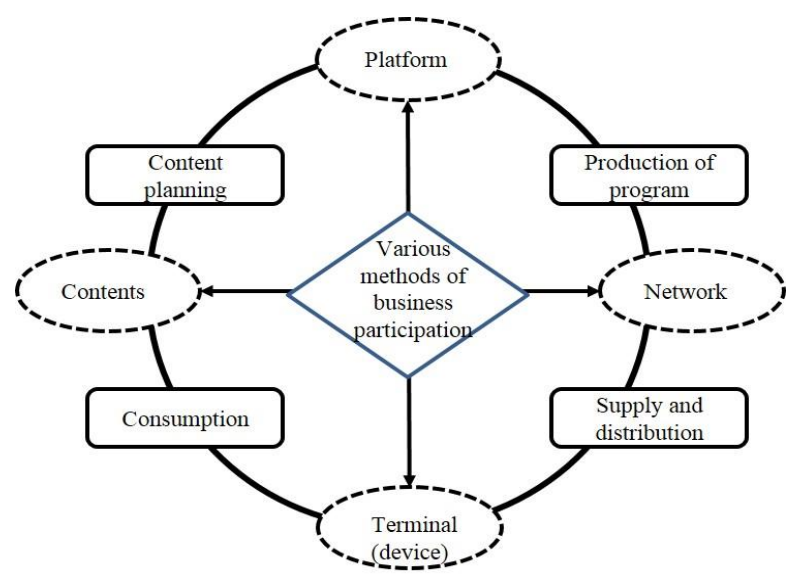

Figure 2. Broadcast and Communications Media Convergence Value Chain as Evolved from the Traditional Value Chain

What first characterizes the broadcast and communications convergence media value chain shown in Figure 2 is how, through the advent of multilateral transmission, an increase in channels, and the variety of distribution methods, traditional content provided exclusively by media service suppliers in the past can now be produced in greater variety and transmitted more openly. Because of the development of new formats and forms, media no longer need to 
be limited to one platform. The second characteristic is the new variety in services and platforms, including the TPS (the triple-play service based on the Internet, telephone, and broadcasting) and the QPS (TPS + mobile), and here packaging, service provision, and transmission are being handled in a single stage. The third characteristic is the development of various networks. With media-to-media, short-range and long-range transmission and advances in the speed of transmission, vast amounts of content can now be enjoyed quickly. The fourth characteristic is how new devices have evolved from being simply media for content consumption to being gateways for content production by users, strengthening their control [20].

\subsection{Broadcast and Communications Media Convergence Technologies and the Media Convergence Value Chain}

This paper restructures the core technological elements of the domestic broadcasting and communications industries up to 2030 by taking into consideration future broadcast and communications technologies and policies in the era of smart media [5, 21, 22]. Media convergence technologies are divided into media convergence expression, informationprocessing, content, content and information security, and transmission and linkage technologies, and each category is examined by domestic experts and consultants in broadcasting and communications fields. Figure 4 takes the evolved media convergence value chain in Figure 3 into consideration to show how these five influences and fuse in the evolved value chain model $[23,24]$. In addition, the figure shows how changes and developments in technological environments in turn change and fuse economic value chains.

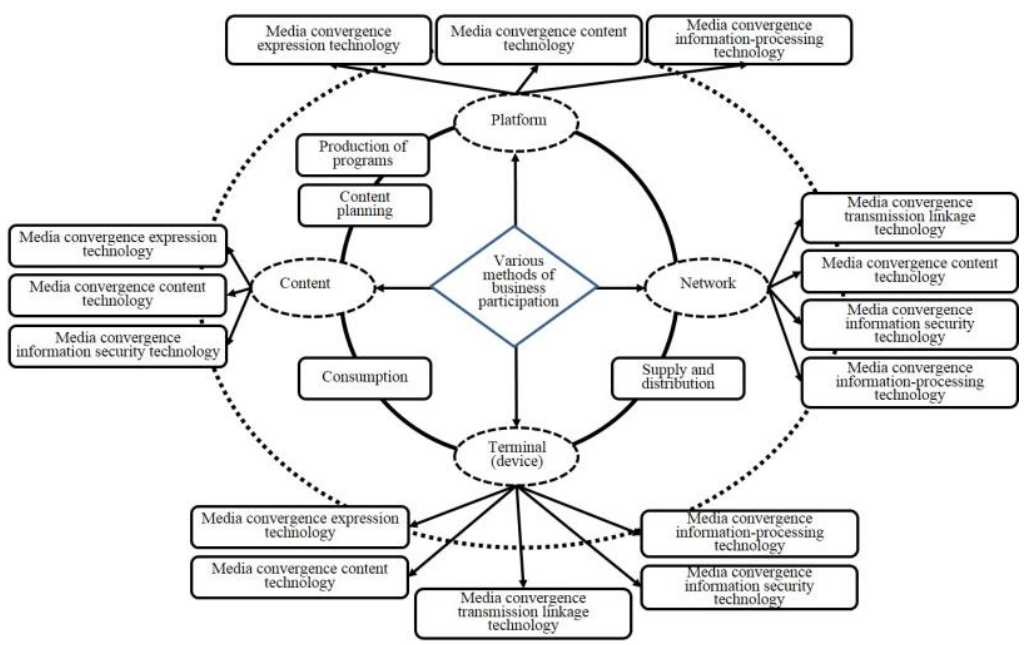

Figure 3. Media Convergence Value Chain Based on Broadcast and Communications Media Convergence Technologies

Unlike Figure 2, Figure 3 combines the content-planning and production stages into a single stage because of advances in the first-level planning stage of high-concept, high-touch content technologies that combine technologies with emotions (a meeting of the story, harmony, empathic immersion, play, and meaning) to increase the number of production activities that require the participation of the user from planning to production. Therefore, with the convergence of the content-planning and development stages and consequent accelerated feedback between users and producers, better-quality production efforts are being realized. In addition, information security measures such as watermarks, trademarks, and 
encryption must take place early to further ensure security later in the creation process. Those media convergence technologies that influence content production technologies include, according to the platform, media convergence expression, content, and information security technologies.

More complex content production expands in the second level, and content provided only in limited forms exclusively through media service providers in the past is now being exchanged in open and bilateral ways because of various service platform and information transmission/linkage technologies. The production process in the second level and the supply and distribution process in the third level in the old value chain are also converging, with media convergence expression, content, and information-processing technologies included in this recombinant stage.

The fourth level of the old value chain combines with the first level because consumers now also act as producers through their new devices. Consumers of content can now use their devices to directly participate in content production as well as to share and sell their content because new systems enable greater interactions between actors as well as maintain competitive and cooperative relationships. This level includes media convergence expression, content, transmission and linkage, information security, and information-processing technologies.

\section{Technologies Related to Broadcast and Communications Media Convergence}

\subsection{Development Aim of Broadcast and Communications Media Convergence Technologies}

The main point from in the structure of the media convergence value chain influenced by the development of broadcast and communications media convergence technologies is the change in the way content is received. Before 2006, television and audio technologies enabled only one-sided, low-resolution communication activities, but they have evolved into HDTV, IPTV, and internet broadcast technologies, making bilateral communications possible. In addition, consumers' content acquisition routes have changed from having-to-choose to having-tailored methods. New media devices that better stimulate the user's senses have emerged, such as UDTV, 3DTV, multi-view TV, and realistic media. These media device technologies predict changes in information transmission in which users can make and experience content in a more creative manner [2]. Figure 4 shows the road map of broadcast and communications convergent media in which technologies inevitably lead to the development of creative industries reflecting the convergence of broadcast and communications media technologies. 


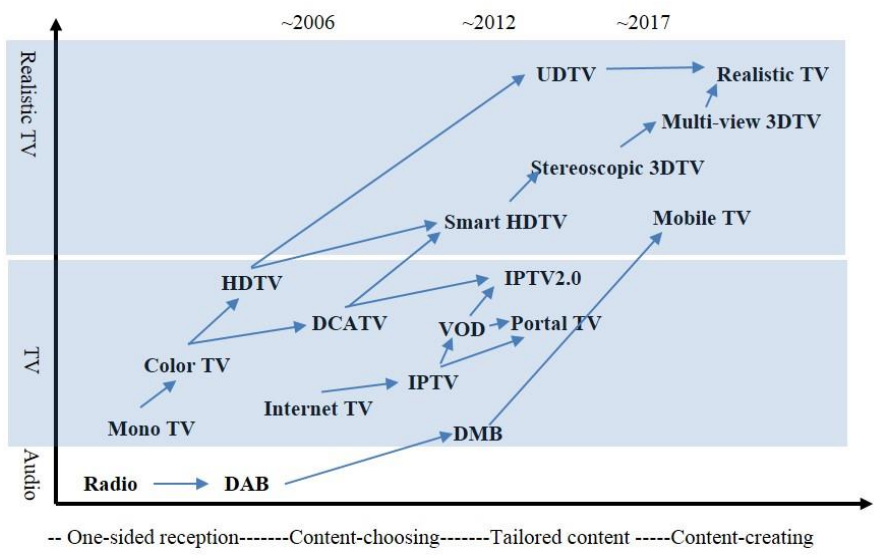

Figure 4. Development Background of Creative Content in Broadcasting and Communications Industries, (reference: 2010 Conference of KAIT)

\subsection{Categories and Definitions of Broadcast and Communications Media Convergence Technologies}

This section classifies the infrastructure-based broadcast and communications media convergence technologies needed for the ultimate "content creation" stage in Figure 4 (see Table 2). These categories include media convergence expression, information-processing, content, content and information security, and transmission and linkage technologies. Their subcategories are arranged in Table 1, which uses the technology classification Table in the ETRI Predicted Technologies Report as its guide [22]. These more specific technologies with vague boundaries between one another because fused technologies are marked as "software/content," "software/hardware convergence," and "broadcast and communications convergence." These areas can be explained through the "software/content technology," "software/hardware convergence in media development," and "information-processing related to distribution/retail transmission and linkage technologies" categories, which are all included in the planning and production stages based on the media convergence value chain and thus classified for a better understanding of their place in the value chain. Table 1 analyzes the importance of specific technologies to prioritize their support and expansion under the science and technology policy. The position of technologies in the media convergence value chain is identified, and their economic impact is analyzed.

Table 1. Definitions of Broadcast and Communications Media Convergence Technologies

\begin{tabular}{|c|c|c|c|}
\hline \multicolumn{2}{|c|}{ Technology Area } & $\begin{array}{c}\text { Specific } \\
\text { Technology }\end{array}$ & Content \\
\hline \multirow{3}{*}{ 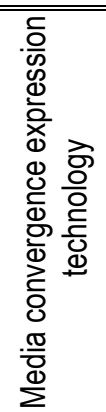 } & \multirow{3}{*}{$\begin{array}{c}\text { Broadcasting } \\
\text { and } \\
\text { Communicatio } \\
\text { ns } \\
\text { convergence }\end{array}$} & $\begin{array}{l}\text { Broadcasting } \\
\text { MRT-based } \\
\text { transmission } \\
\text { system } \\
\text { technology }\end{array}$ & $\begin{array}{l}\text { Multiplexers or 3DTV encoders that can enable non-real-time } \\
\text { broadcasting-based 3D augmented data to be pre- } \\
\text { transmitted and linked to digital broadcasting programs }\end{array}$ \\
\hline & & $\begin{array}{l}\text { Dual-stream } \\
\text { 3DTV } \\
\text { broadcasting } \\
\text { monitoring }\end{array}$ & $\begin{array}{l}\text { A technology that can decode and monitor/analyze dual- } \\
\text { stream 3DTV broadcasting on a real-time basis as well as } \\
\text { automatically detect and correct errors }\end{array}$ \\
\hline & & Dual-parallax & A technology that determines the position of the viewer to \\
\hline
\end{tabular}




\begin{tabular}{|c|c|c|c|}
\hline & & $\begin{array}{l}\text { multiview } \\
\text { display }\end{array}$ & $\begin{array}{l}\text { optimally process a 3D display such that it not only takes } \\
\text { care of the viewer's field of vision but also provides an } \\
\text { interface technology for determining the viewer's position }\end{array}$ \\
\hline & & $\begin{array}{l}\text { Multi-view 3D } \\
\text { face generation }\end{array}$ & $\begin{array}{l}\text { A technology that uses multi-view videos to generate 3D } \\
\text { faces and textures and employs restored 3D facial data on } \\
\text { facial expression templates to create various 3D faces }\end{array}$ \\
\hline & \multirow{2}{*}{$\begin{array}{l}\text { Software/cont } \\
\quad \text { ent } \\
\text { convergence }\end{array}$} & $\begin{array}{l}\text { Real-3D } \\
\text { holograph } \\
\text { technology }\end{array}$ & $\begin{array}{l}\text { A technology using holograms to provide immersive and life- } \\
\text { like videos }\end{array}$ \\
\hline & & $\begin{array}{l}\text { 5-senses 3-D } \\
\text { display } \\
\text { technology }\end{array}$ & $\begin{array}{l}\text { 3D videos that not only provide life-like vision but also stimuli } \\
\text { for the other senses (e.g., touch and smell) }\end{array}$ \\
\hline & $\begin{array}{l}\text { Software/hard } \\
\quad \text { ware } \\
\text { convergence }\end{array}$ & $\begin{array}{l}\text { Wearable- } \\
\text { device } \\
\text { technology }\end{array}$ & $\begin{array}{l}\text { A technology that tracks and transmits biological data for } \\
\text { healthcare- and fitness-related purposes, such as glucose } \\
\text { and heartbeat monitors }\end{array}$ \\
\hline \multirow{5}{*}{ 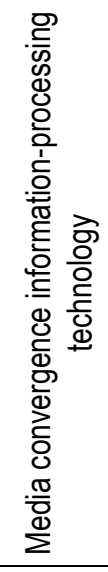 } & \multirow{3}{*}{$\begin{array}{l}\text { Software/hard } \\
\quad \text { ware } \\
\text { convergence }\end{array}$} & $\begin{array}{l}\text { Smart TV STB } \\
\text { technology }\end{array}$ & $\begin{array}{l}\text { A technology that develops smart TV functions, providing set- } \\
\text { top boxes as well as next-generation smart TV sets }\end{array}$ \\
\hline & & $\begin{array}{l}\text { Smart TV set- } \\
\text { top box and } \\
\text { home device } \\
\text { interface }\end{array}$ & $\begin{array}{l}\text { Server systems that develop the interface between smart set- } \\
\text { top boxes/home devices, smart TV applications, and home } \\
\text { network servers based on set-top box platforms }\end{array}$ \\
\hline & & Multicast control & $\begin{array}{l}\text { A technology that enables the invitation of others to services } \\
\text { being used or the distribution of content to others }\end{array}$ \\
\hline & \multirow{2}{*}{$\begin{array}{l}\text { Software/cont } \\
\quad \text { ent } \\
\text { convergence }\end{array}$} & $\begin{array}{l}\text { User emotion } \\
\text { detection } \\
\text { technology }\end{array}$ & $\begin{array}{l}\text { A biosensor technology that analyzes changes in the user's } \\
\text { emotion by detecting changes in his or her speech, facial } \\
\text { expressions, and biological signals }\end{array}$ \\
\hline & & $\begin{array}{l}\text { User-adaptive } \\
\text { technology }\end{array}$ & $\begin{array}{l}\text { A technology that understands the user's interest on a real- } \\
\text { time basis and supports him or her by presenting the most } \\
\text { representative scenarios for user efficiency }\end{array}$ \\
\hline \multirow{6}{*}{ 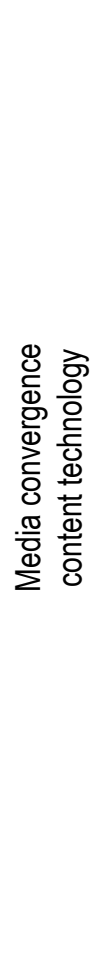 } & $\begin{array}{l}\text { Broadcasting } \\
\text { and } \\
\text { communicatio } \\
\text { ns } \\
\text { convergence }\end{array}$ & $\begin{array}{l}\text { Dual-stream } \\
\text { S3DTV re- } \\
\text { multiplexing }\end{array}$ & $\begin{array}{l}\text { A technology that synchronizes and multiplexes dual-stream } \\
\text { S3DTV in which right and left videos are transmitted in } \\
\text { independent and compressed streams (a re-multiplexing } \\
\text { technology that can generate and insert signaling information } \\
\text { in accordance with S3DTV transmission protocols) }\end{array}$ \\
\hline & \multirow{3}{*}{$\begin{array}{l}\text { Software/cont } \\
\quad \text { ent } \\
\text { convergence }\end{array}$} & $\begin{array}{l}360 \text { video and } \\
3 D \text { scanning } \\
\text { data-based 3D } \\
\text { modeling } \\
\text { technology }\end{array}$ & $\begin{array}{l}\text { A technology that uses 3D scanning data and multi-view } \\
\text { videos to generate 3D modeling and textures for simple 3D } \\
\text { models (a 3D reconstruction technology) }\end{array}$ \\
\hline & & $\begin{array}{l}\text { UI/UX } \\
\text { technology } \\
\text { responding to } \\
\text { the user's } \\
\text { motion }\end{array}$ & $\begin{array}{l}\text { A technology that can discern the user's movement and use } \\
\text { it to process } 3 D \text { content without needing to attach any } \\
\text { wearable equipment on the user }\end{array}$ \\
\hline & & $\begin{array}{l}\text { Digital nature } \\
\text { production } \\
\text { technology for } \\
\text { CG videos }\end{array}$ & $\begin{array}{l}\text { An all-in-one digital nature production solution that enhances } \\
\text { the efficiency and quality of user-centric manipulation-ready } \\
\text { 3D natural environment modeling/placing and editing }\end{array}$ \\
\hline & \multirow{2}{*}{$\begin{array}{l}\text { Software/hard } \\
\quad \text { ware } \\
\text { convergence }\end{array}$} & $\begin{array}{l}\text { H.265 UDTV } \\
\text { compression }\end{array}$ & $\begin{array}{l}\text { A technology that can } \mathrm{H} .265 \text { compress and transmit data that } \\
\text { are } 16 \text { times higher in resolution (1680x4320,32 megapixels) } \\
\text { than current HD }\end{array}$ \\
\hline & & Scalable video & $\log y$ \\
\hline
\end{tabular}




\begin{tabular}{|c|c|c|c|}
\hline & & coding & bitstreams to viewable videos \\
\hline & & $\begin{array}{l}\text { Metadata } \\
\text { processing }\end{array}$ & $\begin{array}{l}\text { A technology that chooses for the user according to his or } \\
\text { her taste from the plethora of broadcast, satellite, and cable } \\
\text { TV channels }\end{array}$ \\
\hline & & $\begin{array}{l}\text { Seamless } \\
\text { content } \\
\text { processing }\end{array}$ & $\begin{array}{l}\text { A technology that enables the seamless sharing of high- } \\
\text { resolution videos between different device platforms in a } \\
\text { network convergence environment through an emotion- } \\
\text { based reality (a new power transmission technology requiring } \\
\text { low power) }\end{array}$ \\
\hline \multirow{8}{*}{ 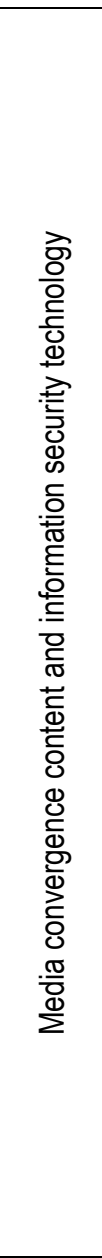 } & \multirow[b]{2}{*}{$\begin{array}{l}\text { Software/cont } \\
\text { ent } \\
\text { convergence }\end{array}$} & $\begin{array}{l}2 \mathrm{~K} / 3 \mathrm{D} \text { digital } \\
\text { cinema } \\
\text { technology }\end{array}$ & $\begin{array}{l}\text { A technology that provides, distributes, manages, and } \\
\text { transmits on a real-time basis life-like and immersive 2K/3D } \\
\text { high-resolution digital cinema content services }\end{array}$ \\
\hline & & $\begin{array}{l}\text { Body avatar } \\
\text { generation } \\
\text { based on real- } \\
\quad \text { life } \\
\text { measurements }\end{array}$ & $\begin{array}{l}\text { A technology that generates personal avatars by calculating } \\
\text { the user's measurements (height, width) from videos taken } \\
\text { from different multi-view cameras (DSLR, Kinect) }\end{array}$ \\
\hline & \multirow{6}{*}{$\begin{array}{l}\text { Software/hard } \\
\quad \text { ware } \\
\text { convergence }\end{array}$} & $\begin{array}{l}\text { Long-range } \\
\text { facial } \\
\text { recognition and } \\
\text { facial database } \\
\text { search }\end{array}$ & $\begin{array}{l}\text { A technology that extracts facial data from long-range videos } \\
\text { and discerns faces from searchable databases }\end{array}$ \\
\hline & & $\begin{array}{l}\text { Fixed-PTZ } \\
\text { camera-based } \\
\text { person/facial } \\
\text { recognition }\end{array}$ & $\begin{array}{l}\text { PTZ (pan, tilt, zoom) cameras that work together over a long } \\
\text { range (over } 5 \mathrm{~m} \text { ) to extract facial data from subjects (faces) }\end{array}$ \\
\hline & & $\begin{array}{l}\text { Comprehensive } \\
\text { system-wide } \\
\text { security }\end{array}$ & $\begin{array}{c}\text { A core technology that enables independent domains such } \\
\text { as ISPs to safely share information to collectively act against } \\
\text { cyber-terrorism }\end{array}$ \\
\hline & & $\begin{array}{l}\text { DRM } \\
\text { technology }\end{array}$ & $\begin{array}{l}\text { A technology that provides a framework for distributing digital } \\
\text { content, supporting retail operations, controlling various } \\
\text { access rights, and providing encryption for internet, intranet, } \\
\text { and other communications networks }\end{array}$ \\
\hline & & $\begin{array}{l}\text { Situation } \\
\text { recognition } \\
\text { security }\end{array}$ & $\begin{array}{l}\text { A technology that detects and analyzes network anomalies } \\
\text { on a real-time basis and clearly shows the country and } \\
\text { location of the attacker }\end{array}$ \\
\hline & & $\begin{array}{l}\text { Ubiquitous } \\
\text { home } \\
\text { information } \\
\text { security }\end{array}$ & $\begin{array}{l}\text { A technology that provides health information, among others, } \\
\text { from various and various sources of data (situations of } \\
\text { people, objects, or environments) collected from subjects } \\
\text { occupying a ubiquitous technology environment }\end{array}$ \\
\hline \multirow{5}{*}{ 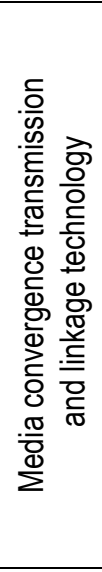 } & \multirow{5}{*}{$\begin{array}{l}\text { Broadcasting } \\
\text { and } \\
\text { communicatio } \\
\text { ns } \\
\text { convergence }\end{array}$} & $\begin{array}{l}\text { Transmission of } \\
\text { high-speed } \\
\text { remote videos } \\
\text { from Windows } \\
\text { servers }\end{array}$ & $\begin{array}{l}\text { A technology that enables the transmission of high-speed } \\
\text { remote videos from Windows servers }\end{array}$ \\
\hline & & $\begin{array}{c}\text { Omni10 } \\
\text { platform } \\
\text { technology }\end{array}$ & $\begin{array}{l}\text { A technology that enables } L 2 \sim \text { L7 packet processing at the } \\
\text { core of next-generation networks }\end{array}$ \\
\hline & & IPv6 transition & $\begin{array}{c}\text { A technology that enables IPv4-based network systems to } \\
\text { use newer IPv6 addresses }\end{array}$ \\
\hline & & Mobile IPTV & $\begin{array}{l}\text { An IPTV technology that uses wireless communications } \\
\text { technologies such as WiMax (or Wibro in Korea), 3GPP, } \\
\text { 3GPP2, and DVB }\end{array}$ \\
\hline & & Smart agent & Private devices that can independently act and decide on the \\
\hline
\end{tabular}




\begin{tabular}{|c|c|c|}
\hline \multirow{2}{*}{} & technology & user's needs \\
\cline { 2 - 3 } & LBS & $\begin{array}{c}\text { Systems or services that uses location detection and } \\
\text { communications networks to track the location of people or } \\
\text { objects and employs this information by providing relevant } \\
\text { information on the location to users in motion }\end{array}$ \\
\hline
\end{tabular}

\section{Analysis of the Importance of Broadcast and Communications Media Convergence Technologies}

\subsection{AHP Analysis}

The AHP method divides the whole decision-making process into various levels and analyzes and resolves by level to reach a final decision. The most important characteristic of this method is how it breaks down complex problems into main and detailed causes and uses a pairwise comparison to discern their importance. This method is notable for how it uses a process similar to the human mind in how it analyzes and structuralizes a problem and for how it employs models to organize the importance of or preference for main and detailed causes according to a ratio scale to produce quantifiable results. Theoretically, the method employs various techniques used for selecting yardsticks, calculating weight, and analyzing responsiveness after they are put through an empirical analysis and mathematical verification. Because of these merits, the method has been used in various contexts, including the selection of new technologies, the design of hospital service systems, the resolution of political disputes, and decision making, e.g., the Sudanese traffic system undertaken by Satty in 1977 [25].

The AHP method normally consists of the following five steps: setting goals and discerning decision-making elements, setting a decision-making model, providing a pairwise comparison of elements, verifying logical consistency, and producing consolidated/group decision results.

i) Stage 1: Setting goals and discerning decision-making elements

This stage defines the decision-making goal through brainstorming, literature reviews, and consultation with experts. It then discerns alternative decision-making objectives and lays out criteria for the evaluation of each alternative.

ii) Stage 2: Setting a decision-making model

This stage establishes a decision hierarchy that includes goals, evaluation standards and alternatives. Various other elements (e.g., actors and scenarios) can also be included, and subjects of comparison must not exceed nine per evaluation standard.

iii) Stage 3: Providing a pairwise comparison of elements

This stage evaluates the importance of or preference for decision-making elements through a 1:1 pairwise comparison with a higher-level element. In other words, it compares the evaluation standard against the goal, the evaluation against the (higher) evaluation standard, and alternatives against the evaluation standard. This stage maximizes the use of the factual material, knowledge, experience, and intuition to comprehensively evaluate the issue and uses a 1-9 scale and an eigenvector method to find the weight for all elements. Finally, eigenvalues of lower and higher levels are multiplied to calculate the final weight of the decision alternative [26].

This paper employs the eigenvalue calculation method as follows:

Step 1: Find a matrix of the level's element $\boldsymbol{A}=\left[\boldsymbol{\alpha i}_{\boldsymbol{i}} \boldsymbol{j}^{\prime}\right]$ through a pairwise comparison: 


$$
\text { Note that } a i j=\frac{1}{a_{i j}}
$$

Step 2: Designate $n$ elements as $\boldsymbol{A}_{1}, \boldsymbol{A}_{2}, \boldsymbol{A}_{3} \ldots \boldsymbol{A}_{n}$ and the importance of each element as $\boldsymbol{w}_{1}, \boldsymbol{w}_{2}, \boldsymbol{w}_{3} \ldots \boldsymbol{w}_{n}$ to create the following matrix through a pairwise comparison:

$$
\begin{gathered}
A_{1} \\
A_{1} \\
A_{2} \\
A_{3} \\
A_{3} \\
A_{n}
\end{gathered}\left[\begin{array}{ccccc}
w_{1} / w_{1} & w_{1} / w_{2} & w_{1} / w_{3} & \ldots & w_{1} / w_{n} \\
w_{2} / w_{1} & w_{2} / w_{2} & w_{2} / w_{3} & \ldots & w_{2} / w_{n} \\
w_{3} / w_{1} & w_{3} / w_{2} & w_{3} / w_{3} & \ldots & w_{3} / w_{n} \\
\vdots & \vdots & \vdots & \ldots & \vdots \\
w_{n} / w_{1} & w_{n} / w_{2} & w_{n} / w_{3} & \ldots & w_{n} / w_{n}
\end{array}\right],
$$

Step 3: Calculate eigenvalues to produce a weight matrix $(\boldsymbol{W})$. The eigenvalue is what solves $\left|\boldsymbol{A}^{\prime}-\boldsymbol{\lambda}\right|=\mathbf{0}$, and if there are multiple answers, then the largest number is set as the eigenvalue:

$$
W=\left[\begin{array}{l}
W_{1} \\
W_{2} \\
W_{3}
\end{array}\right] \rightarrow A^{\prime} W=\lambda W \rightarrow\left(A^{\prime}-\lambda \mid\right) W=0,
$$

iv) Stage 4: Verifying logical consistency

To verify the logical consistency of judgments made by decision makers (or survey respondents), this stage verifies the level of consistency by evaluating elements through a pairwise comparison. After the experiment and verification as well as the assessment of evaluation standards and alternatives through a pairwise comparison of participants, certain parts showing low logical consistency are included in feedback to be reevaluated and augmented, thereby increasing the logical consistency of participants and improving the level of inconsistency to the recommended threshold of under 0.1 . The formula for calculating the level of inconsistency is as follows:

$$
\boldsymbol{C R}=\frac{\boldsymbol{C I}}{\boldsymbol{R I}}, \boldsymbol{C I}=\frac{\lambda-\boldsymbol{n}}{\boldsymbol{n}-\mathbf{1}},(\boldsymbol{\lambda} \text { : eigenvalue, } \boldsymbol{n}: \text { number of elements }),
$$

$\boldsymbol{C R}$ : consistency ratio, $\boldsymbol{C I}$ : consistency index, $\boldsymbol{R} \boldsymbol{I}$ : random index

Table 2. Random Index According to Number of Elements

\begin{tabular}{|c|c|c|c|c|c|c|c|c|c|}
\hline $\mathrm{n}$ & 2 & 3 & 4 & 5 & 6 & 7 & 8 & 9 & 10 \\
\hline \hline $\mathrm{RI}$ & 0.00 & 0.52 & 0.90 & 1.12 & 1.24 & 1.32 & 1.41 & 1.45 & 1.51 \\
\hline
\end{tabular}

v) Stage 5: Producing consolidated/group decision results.

Consolidate pairwise comparison results to discern the importance of each evaluation standard and the optimal alternative (or alternatives according to preferences or importance). These results are shown in 4.4, with the final priority (importance or preference) score for each technology category.

\subsection{Analysis of the Importance of Broadcast and Communications Convergence Technologies}

The objective of this paper is to prioritize various broadcast and communications media convergence technologies to define core technologies that need to be endorsed in future 
technology policies. For this, a survey of experts in various fields covered by broadcast and communications media convergence technologies was conducted from October 8 to 26, 2012. A total of 10 questionnaires were sent to academics, and 6, to research institutions and firms. Among the 16 respondents, 8 were in their fifties (50.0\%); 5, in their forties (31.3\%); and 1, in his or her thirties (6.3\%). In terms of research experience after receiving the $\mathrm{PhD}$ degree, 5 had 5-9 years of research experience $(31.3 \%) ; 5,10-14$ years $(31.3 \%) ; 2,1-5$ years $(12.5 \%)$; and 1, 15-19 years (6.3\%). They were in various fields, including networks, wireless communication signal processing, semiconductor devices, broadcasting and communications, electrical engineering, computer engineering, and communication, and their specialization included broadcasting and communications, transmission/satellites, software, next-generation mobile communications and future networks, convergent technologies, and convergent parts (e.g., new materials and displays).

Table 3. Respondent Profile

\begin{tabular}{|c|c|c|c|c|c|c|c|}
\hline \multicolumn{2}{|c|}{ Demographic } & Frequency & $\begin{array}{l}\text { Percent } \\
\text { age }\end{array}$ & \multicolumn{2}{|c|}{ Demographic } & Frequency & $\begin{array}{l}\text { Perce } \\
\text { ntage }\end{array}$ \\
\hline \multirow[b]{2}{*}{ Work } & Academia & 10 & $62.5 \%$ & \multirow{11}{*}{$\begin{array}{l}\text { Research } \\
\text { area }\end{array}$} & & & \\
\hline & $\begin{array}{l}\text { Research } \\
\text { institution }\end{array}$ & 6 & $37.5 \%$ & & communications & 4 & $21.1 \%$ \\
\hline \multirow{4}{*}{ Age } & $30 \mathrm{~s}$ & 1 & $6.3 \%$ & & \multirow{2}{*}{$\begin{array}{l}\text { Transmission/sate } \\
\text { llites }\end{array}$} & \multirow{2}{*}{3} & \multirow{2}{*}{$15.8 \%$} \\
\hline & $40 \mathrm{~s}$ & 5 & $31.3 \%$ & & & & \\
\hline & $50 \mathrm{~s}$ & 8 & $50.0 \%$ & & \multirow{2}{*}{ Software } & \multirow[b]{2}{*}{5} & \multirow{2}{*}{$26.3 \%$} \\
\hline & No response & 2 & $12.5 \%$ & & & & \\
\hline \multirow{5}{*}{$\begin{array}{l}\text { Years of } \\
\text { work }\end{array}$} & $1 \sim 5$ years & 2 & $12.5 \%$ & & \multirow{2}{*}{$\begin{array}{l}\text { Next-generation } \\
\text { mobile networks }\end{array}$} & \multirow[b]{2}{*}{2} & \multirow{2}{*}{$10.5 \%$} \\
\hline & $5 \sim 9$ years & 5 & $31.3 \%$ & & & & \\
\hline & 10 14 years & 5 & $31.3 \%$ & & \multirow{2}{*}{$\begin{array}{l}\text { Convergent } \\
\text { technology }\end{array}$} & \multirow[b]{2}{*}{3} & \multirow{2}{*}{$15.8 \%$} \\
\hline & 15 18 years & 1 & $6.3 \%$ & & & & \\
\hline & No response & 3 & $18.8 \%$ & & $\begin{array}{l}\text { Convergent parts } \\
\text { (new materials, } \\
\text { etc.) }\end{array}$ & 2 & $10.5 \%$ \\
\hline
\end{tabular}

\subsubsection{Model for Evaluating the Importance of Broadcast and Communications Media Convergence Technologies}

The analysis was conducted using a prioritization evaluation model with the categories of the importance of broadcast and communications media convergence technologies divided into two upper categories (level 1) and seven lower ones (level 2). The priority (importance) of each evaluation element as well as category was examined using the AHP method, and the definitions and specific evaluation categories for each division are summarized as follows:

Table 4. Model for Evaluating Broadcast and Communications Media Convergence Technologies

\begin{tabular}{|c|l|l|}
\hline $\begin{array}{c}\text { Evaluation } \\
\text { Dategory } \\
\text { (Level 1) }\end{array}$ & $\begin{array}{c}\text { Evaluation } \\
\text { Category } \\
\text { (Level 2) }\end{array}$ & \multicolumn{1}{|c|}{ Details } \\
\hline \hline \multirow{2}{*}{$\begin{array}{l}\text { Technological } \\
\text { aspects }\end{array}$} & $\begin{array}{l}\text { Technological } \\
\text { impact }\end{array}$ & $\begin{array}{l}\text { Broadcast and communications media convergence technologies that } \\
\text { can expand scientific frontiers and basic science }\end{array}$ \\
\cline { 2 - 3 } & $\begin{array}{l}\text { Technological } \\
\text { progressiveness }\end{array}$ & $\begin{array}{l}\text { Broadcast and communications media convergence technologies that } \\
\text { can influence technological progress in relevant areas }\end{array}$ \\
\hline
\end{tabular}




\begin{tabular}{|l|l|l|}
\hline \multirow{5}{*}{$\begin{array}{l}\text { Socioeconomic } \\
\text { aspects }\end{array}$} & $\begin{array}{l}\text { Technological } \\
\text { need }\end{array}$ & $\begin{array}{l}\text { Broadcast and communications media convergence technologies that } \\
\text { are in high demand in relevant areas }\end{array}$ \\
\cline { 2 - 3 } & $\begin{array}{l}\text { Technological } \\
\text { feasibility }\end{array}$ & $\begin{array}{l}\text { Broadcast and communications media convergence technologies that } \\
\text { are technologically feasible }\end{array}$ \\
\hline & $\begin{array}{l}\text { Socioeconomic } \\
\text { urgency }\end{array}$ & $\begin{array}{l}\text { Broadcast and communications media convergence technologies that } \\
\text { need to respond swiftly to rapidly changing technologies and economic } \\
\text { environments }\end{array}$ \\
\cline { 2 - 3 } & $\begin{array}{l}\text { Socioeconomic } \\
\text { need }\end{array}$ & $\begin{array}{l}\text { Broadcast and communications media convergence technologies } \\
\text { showing great socioeconomic need (and want) in relevant areas }\end{array}$ \\
\cline { 2 - 3 } & $\begin{array}{l}\text { Future } \\
\text { Socioeconomic } \\
\text { value }\end{array}$ & $\begin{array}{l}\text { Broadcast and communications media convergence technologies with } \\
\text { future socioeconomic value }\end{array}$ \\
\hline
\end{tabular}

In the analysis, broadcast and communications media convergence technologies were divided into media convergence expression, information-processing, content, content and information security, and transmission and linkage technologies. These technologies are specified in greater detail in Table 5.

\section{Table 5. Evaluation Categories for Analyzing Broadcast and Communications Media Convergence Technologies}

\begin{tabular}{|c|c|c|}
\hline \multicolumn{2}{|c|}{ Technology Area } & Specific Technologies \\
\hline \multirow{7}{*}{$\begin{array}{l}\text { Media } \\
\text { convergence } \\
\text { expression } \\
\text { technology }\end{array}$} & \multirow{4}{*}{$\begin{array}{l}\text { Broadcasting and } \\
\text { Communications } \\
\text { convergence }\end{array}$} & An MRT-based transmission technology \\
\hline & & $\begin{array}{l}\text { A technology for dual-stream 3DTV transmission } \\
\text { monitoring }\end{array}$ \\
\hline & & A dual-parallax multi-view display technology \\
\hline & & A multi-view 3D face generation technology \\
\hline & \multirow{2}{*}{$\begin{array}{l}\text { Software/content } \\
\text { convergence }\end{array}$} & A real-3D holograph technology \\
\hline & & A 5-senses 3D display technology \\
\hline & $\begin{array}{l}\text { Software/hardware } \\
\text { convergence }\end{array}$ & A wearable-device technology \\
\hline \multirow{5}{*}{$\begin{array}{l}\text { Media } \\
\text { convergence } \\
\text { information- } \\
\text { processing } \\
\text { technology }\end{array}$} & \multirow{3}{*}{$\begin{array}{l}\text { Software/hardware } \\
\text { convergence }\end{array}$} & A smart TV STB technology \\
\hline & & Smart TV set-top box and home device interfaces \\
\hline & & Multicast control systems \\
\hline & \multirow{2}{*}{$\begin{array}{l}\text { Software/content } \\
\text { convergence }\end{array}$} & A technology for detecting the user's emotion \\
\hline & & A user-adaptive technology \\
\hline \multirow{8}{*}{$\begin{array}{l}\text { Media } \\
\text { convergence } \\
\text { content } \\
\text { technology }\end{array}$} & $\begin{array}{l}\text { Broadcasting and } \\
\text { communications } \\
\text { convergence }\end{array}$ & A dual-stream S3DTV re-multiplexing technology \\
\hline & \multirow{3}{*}{$\begin{array}{l}\text { Software/content } \\
\text { convergence }\end{array}$} & $\begin{array}{l}\text { A } 360 \text { video and 3D scanning data-based 3D modeling } \\
\text { technology }\end{array}$ \\
\hline & & A UI/UX technology that responds to the user's motion \\
\hline & & A digital nature production technology for CG videos \\
\hline & \multirow{4}{*}{$\begin{array}{l}\text { Software/hardware } \\
\text { convergence }\end{array}$} & An H.265 UDTV compression technology \\
\hline & & A scalable video-coding technology \\
\hline & & A metadata-processing technology \\
\hline & & A technology for seamless content processing \\
\hline \multirow{4}{*}{$\begin{array}{l}\text { Media } \\
\text { convergence } \\
\text { content and } \\
\text { information } \\
\text { security } \\
\text { technology }\end{array}$} & \multirow[b]{2}{*}{$\begin{array}{l}\text { Software/content } \\
\text { convergence }\end{array}$} & A 2K/3D digital cinema technology \\
\hline & & $\begin{array}{l}\text { A body avatar generation technology based on real-life } \\
\text { measurements }\end{array}$ \\
\hline & \multirow{2}{*}{$\begin{array}{l}\text { Software/hardware } \\
\text { convergence }\end{array}$} & $\begin{array}{l}\text { A technology for long-range facial recognition and facial } \\
\text { database searches }\end{array}$ \\
\hline & & A technology for recognizing fixed-PTZ camera-based \\
\hline
\end{tabular}




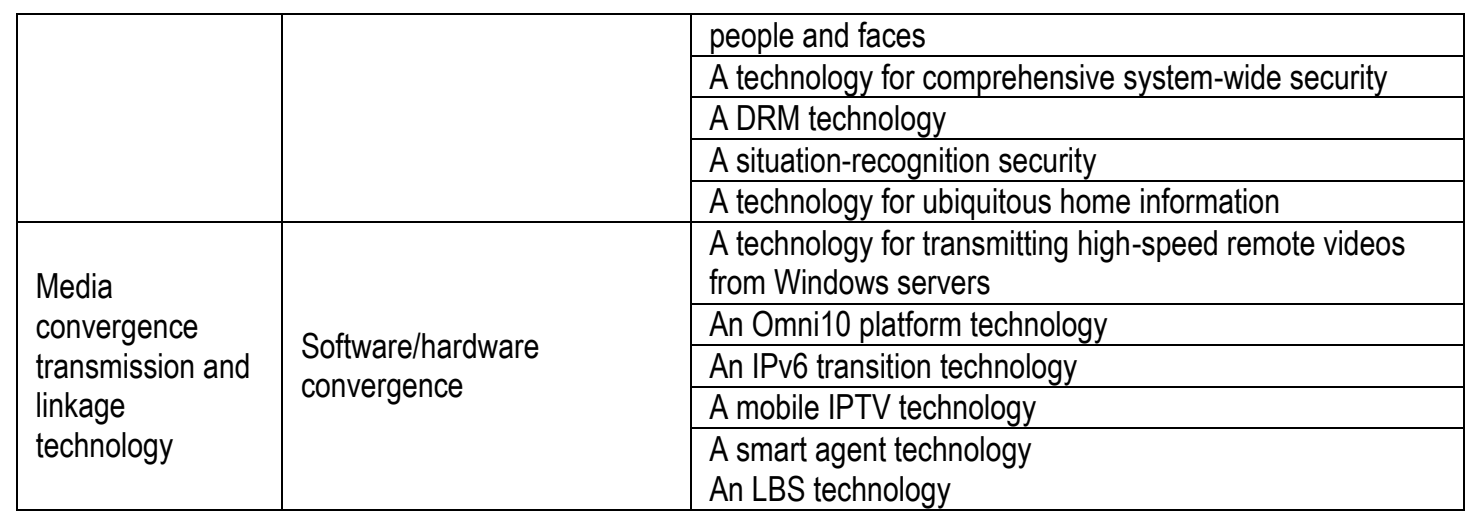

\subsection{Importance of Broadcast and Communications Media Convergence Technologies by Evaluation Category}

(1) Evaluation Categories

Table 6. Importance by Evaluation Category

\begin{tabular}{|l|l|l|c|}
\hline $\begin{array}{c}\text { Evaluation Category } \\
\text { (level 1) }\end{array}$ & Priority & \multicolumn{1}{|c|}{ Evaluation Category (Level 2) } & Priority \\
\hline \multirow{4}{*}{$\begin{array}{l}\text { Technological } \\
\text { Aspects }\end{array}$} & \multirow{3}{*}{0.549} & Technological impact & 0.130 \\
\cline { 3 - 4 } & & Technological progressiveness & 0.109 \\
\cline { 3 - 4 } & & Technological need & 0.180 \\
\cline { 3 - 4 } \multirow{3}{*}{$\begin{array}{l}\text { Socioeconomic } \\
\text { aspects }\end{array}$} & \multirow{2}{*}{0.451} & Technological feasibility & 0.130 \\
\cline { 3 - 4 } & & Socioeconomic urgency & 0.120 \\
\cline { 3 - 4 } & & Socioeconomic need & 0.146 \\
\cline { 3 - 4 } & Future Socioeconomic value & 0.185 \\
\hline
\end{tabular}

(2) Technological Fields by Evaluation Category

Table 7. Importance of Technological Impacts by Technological Field

\begin{tabular}{|l|c|c|c|c|c|c|c|c|}
\hline \multirow{2}{*}{ Technology Area } & \multicolumn{7}{|c|}{ Technological Aspects } & \multicolumn{3}{c|}{ Socioeconomic Aspects } \\
\cline { 2 - 9 } & Impact & $\begin{array}{c}\text { progressiv } \\
\text { eness }\end{array}$ & $\begin{array}{c}\text { Importa } \\
\text { nce }\end{array}$ & $\begin{array}{c}\text { Feasibili } \\
\text { ty }\end{array}$ & Urgency & Need & Value & Total \\
\hline \hline $\begin{array}{l}\text { Media convergence } \\
\text { expression technology }\end{array}$ & 0.111 & 0.316 & 0.124 & 0.156 & 0.190 & 0.176 & 0.335 & 0.202 \\
\hline $\begin{array}{l}\text { Media convergence } \\
\text { information-processing } \\
\text { technology }\end{array}$ & 0.213 & 0.150 & 0.173 & 0.228 & 0.219 & 0.126 & 0.142 & 0.176 \\
\hline $\begin{array}{l}\text { Media convergence } \\
\text { content technology }\end{array}$ & 0.236 & 0.147 & 0.170 & 0.202 & 0.169 & 0.262 & 0.177 & 0.195 \\
\hline $\begin{array}{l}\text { Media convergence } \\
\text { content and information } \\
\text { security technology }\end{array}$ & 0.210 & 0.150 & 0.230 & 0.182 & 0.169 & 0.226 & 0.180 & 0.195 \\
\hline $\begin{array}{l}\text { Media convergence } \\
\text { transmission and } \\
\text { linkage technology }\end{array}$ & 0.231 & 0.238 & 0.304 & 0.232 & 0.253 & 0.209 & 0.165 & 0.232 \\
\hline
\end{tabular}


Media convergence transmission and linkage technologies received high scores for both technological importance (0.304) and socioeconomic urgency (0.253); media convergence expression technologies, for future socioeconomic value (0.335) and technological progressiveness (0.316); media convergence content technologies, for the socioeconomic need (0.262) and technological impacts (0.236); and media convergence content and information security technologies, for the technological need (0.230) and socioeconomic importance (0.226). With the seven evaluation categories and the level of technological importance considered, media convergence transmission and linkage technologies received the highest score (0.232), followed by media convergence expression (0.202), content (0.195), content and information security (0.195), and information-processing (0.176) technologies.

\subsection{Importance of Subcategories of Broadcast and Communications Media Convergence Technologies by Evaluation Category}

With the five levels of technological importance for the seven evaluation categories as well as the prioritization of subcategories of technologies considered, the technologies of the highest priority were the technology for detecting the emotion of users (0.0526), mobile IPTV (0.0453), the user-adaptive technology (0.0435), the real-3D holograph technology (0.0408), the transmission of high-speed remote videos from Windows servers $(0.0413)$, the 5-senses 3D display technology (0.0408), and the IPv6 transition technology (0.0404). All these technologies scored higher than 0.04 and involved the processing of the user's behavioral and emotional data for expressing them in the medium and the rapid transmission of this expression through various media platforms. From the perspective of the value chain infrastructure, the technologies playing crucial roles in the planning/digitalization, content production, and content transmission stages were media convergence information-processing, expression, and transmission and linkage technologies, which also played crucial roles in all stages of the CPNT value chain.

Table 8. Importance of Technology Areas and Subcategories

\begin{tabular}{|c|c|c|c|c|c|}
\hline $\begin{array}{l}\text { Technol } \\
\text { ogy Area }\end{array}$ & Priority & & Technology Subcategory & Priority & $\begin{array}{l}\text { Priority } \\
\text { Total }\end{array}$ \\
\hline \multirow{7}{*}{ 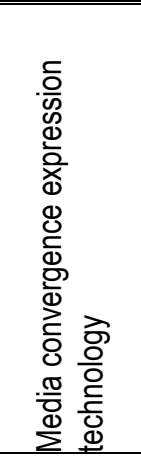 } & \multirow{7}{*}{0.202} & \multirow{4}{*}{$\begin{array}{l}\text { Broadcasting } \\
\text { and } \\
\text { Communicati } \\
\text { ons } \\
\text { convergence } \\
\end{array}$} & An MRT-based transmission technology & 0.135 & 0.0273 \\
\hline & & & $\begin{array}{l}\text { A technology for dual-stream 3DTV } \\
\text { transmission monitoring }\end{array}$ & 0.095 & 0.0192 \\
\hline & & & A dual-parallax multi-view display technology & 0.109 & 0.0220 \\
\hline & & & A multi-view 3D face generation technology & 0.124 & 0.0250 \\
\hline & & \multirow{2}{*}{$\begin{array}{l}\text { Software/con } \\
\text { tent } \\
\text { convergence }\end{array}$} & A real-3D holograph technology & 0.206 & 0.0416 \\
\hline & & & A 5-senses 3D display technology & 0.202 & 0.0408 \\
\hline & & $\begin{array}{l}\text { Software/har } \\
\text { dware } \\
\text { convergence }\end{array}$ & A wearable-device technology & 0.129 & 0.0261 \\
\hline \multirow{5}{*}{ 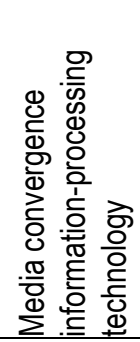 } & \multirow{5}{*}{0.176} & \multirow{5}{*}{$\begin{array}{l}\text { Software/har } \\
\text { dware } \\
\text { convergence } \\
\text { Software/con } \\
\text { tent } \\
\text { convergence }\end{array}$} & A smart TV STB technology & 0.152 & 0.0267 \\
\hline & & & $\begin{array}{l}\begin{array}{l}\text { Smart TV set-top box and home device } \\
\text { interfaces }\end{array} \\
\end{array}$ & 0.170 & 0.0299 \\
\hline & & & Multicast control systems & 0.131 & 0.0230 \\
\hline & & & A technology for detecting the user's emotion & 0.299 & 0.0526 \\
\hline & & & A user-adaptive technology & 0.248 & 0.0436 \\
\hline
\end{tabular}




\begin{tabular}{|c|c|c|c|c|c|}
\hline \multirow{8}{*}{ 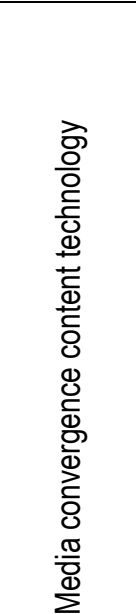 } & \multirow{8}{*}{0.195} & $\begin{array}{l}\text { Broadcasting } \\
\text { and } \\
\text { communicati } \\
\text { ons } \\
\text { convergence }\end{array}$ & $\begin{array}{l}\text { A dual-stream S3DTV re-multiplexing } \\
\text { technology }\end{array}$ & 0.108 & 0.0210 \\
\hline & & \multirow{3}{*}{$\begin{array}{l}\text { Software/con } \\
\text { tent } \\
\text { convergence }\end{array}$} & $\begin{array}{l}\text { A } 360 \text { video and 3D scanning data-based 3D } \\
\text { modeling technology }\end{array}$ & 0.153 & 0.0298 \\
\hline & & & $\begin{array}{l}\text { A UI/UX technology that responds to the user's } \\
\text { motion }\end{array}$ & 0.110 & 0.0214 \\
\hline & & & $\begin{array}{l}\text { A digital nature production technology for CG } \\
\text { videos }\end{array}$ & 0.116 & 0.0226 \\
\hline & & \multirow{4}{*}{$\begin{array}{l}\text { Software/har } \\
\text { dware } \\
\text { convergence }\end{array}$} & An H.265 UDTV compression technology & 0.158 & 0.0308 \\
\hline & & & A scalable video-coding technology & 0.143 & 0.0279 \\
\hline & & & A metadata-processing technology & 0.093 & 0.0181 \\
\hline & & & A technology for seamless content processing & 0.119 & 0.0232 \\
\hline \multirow{8}{*}{ 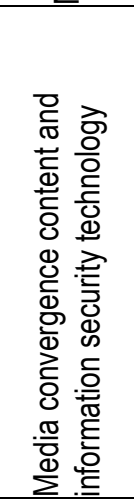 } & \multirow{8}{*}{0.195} & \multirow{2}{*}{$\begin{array}{l}\text { Software/con } \\
\text { tent } \\
\text { convergence }\end{array}$} & A 2K/3D digital cinema technology & 0.164 & 0.0320 \\
\hline & & & $\begin{array}{l}\text { A body avatar generation technology based on } \\
\text { real-life measurements }\end{array}$ & 0.143 & 0.0279 \\
\hline & & \multirow{6}{*}{$\begin{array}{l}\text { Software/har } \\
\text { dware } \\
\text { convergence }\end{array}$} & $\begin{array}{l}\text { A technology for long-range facial recognition } \\
\text { and facial database searches }\end{array}$ & 0.141 & 0.0275 \\
\hline & & & $\begin{array}{l}\text { A technology for recognizing fixed-PTZ camera- } \\
\text { based people and faces }\end{array}$ & 0.144 & 0.0281 \\
\hline & & & $\begin{array}{l}\text { A technology for comprehensive system-wide } \\
\text { security }\end{array}$ & 0.098 & 0.0191 \\
\hline & & & A DRM technology & 0.102 & 0.0199 \\
\hline & & & A situation-recognition security & 0.129 & 0.0252 \\
\hline & & & A technology for ubiquitous home information & 0.078 & 0.0152 \\
\hline \multirow{6}{*}{ 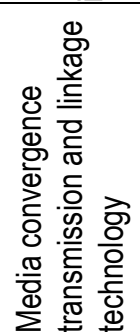 } & \multirow{6}{*}{0.232} & \multirow{6}{*}{$\begin{array}{l}\text { Software/har } \\
\text { dware } \\
\text { convergence }\end{array}$} & $\begin{array}{l}\text { A technology for transmitting high-speed remote } \\
\text { videos from Windows servers }\end{array}$ & 0.178 & 0.0413 \\
\hline & & & An Omni10 platform technology & 0.162 & 0.0376 \\
\hline & & & An IPv6 transition technology & 0.174 & 0.0404 \\
\hline & & & A mobile IPTV technology & 0.195 & 0.0453 \\
\hline & & & $\begin{array}{l}\text { A smart agent technology } \\
\text { An LBS technology }\end{array}$ & 0.121 & 0.0281 \\
\hline & & & An Omni10 platform technology & 0.171 & 0.0397 \\
\hline
\end{tabular}

\section{Conclusion}

According to the results for subcategories of the importance of technologies, those technologies with the highest scores (the technology for detecting the emotion of users and the user-adaptive technology) were included in the category of media convergence information-processing technologies, but media convergence information-processing technologies were also included in the category of media convergence transmission and linkage technologies, which enable the conversion and transmission of digitalized patterns of behaviors and emotions of users in a bidirectional, not traditionally unilateral, manner. This convergence of diverse technologies can enable the fusion of the traditional planning, production, distribution, and consumption stages of the value chain. All IP technologies require IPv6 to be realized, and its importance is reflected by its rank (seventh) in Table 9. IPv6 is an integral part of convergent media transmission and linkage technologies conceived because the existing IPv4 protocol for device compatibility is generally deemed insufficient for the rapidly increasing number of devices and systems. In addition, the development of this technology is related to the personal area network (PAN), which refers to a wireless network 
technology for controlling various devices (e.g., phones, smart pads, and computers) within the environment of a single individual. With these transmission technologies as the base, the smart agent technology and the location-based service (LBS) are expected to improve for the better compatibility and linkage of diversified transmission networks. Ultimately, advances in media convergence transmission and linkage technologies should provide a seamless environment where 3D information caters to all five senses. As shown in Table 9, the smart agent technology and the LBS indeed took the highest priority. Media convergence information-processing technologies include processing and compatibility middleware for 3D and set-top box (STB) graphics and are actually basic technologies for the transmission of sensory information on users. Because users prefer to interact with sensory information in an interactive manner, those technologies for detecting the emotion of users or adapting to them ranked first and third, respectively. Real 3D, which uses detected data to stimulate sight and sound, is being developed in tandem with 5-senses 3D displays, and ranked fourth and sixth, respectively. These results indicate that the technologies that need to be developed first are media convergence transmission and linkage technologies, which establish network environments that can seamlessly transmit emotional and adaptive data from users, and media convergence expression technologies, which enable users to experience content with all their senses.

Based on these results, the technological impact of each technology can be arranged according to its importance into a convergent ecosystem, as shown in Figure 7. This ecosystem takes into account detailed relationships between these technologies and shows how each stage of the circulatory value chain ecosystem can also be thought of as its own value chain.

The convergent ecosystem shown in Figure 7 makes it clear that the progress of these technologies can make it possible for the dynamic evolution of the value chain of creativecontent industries. In addition, it shows that industries based on creative work, also known as creative, culture, or entertainment industries, are greatly influenced by technological advances. Based on the content development, service platform, supply network, and use (device) stages, it is possible to see how all five subcategories of broadcast and communications media convergence technologies are included in the service platform and use stages. In other words, this shows that content users not only are also content producers but also take part in distributing their content. Therefore, the change in the value chain structure makes it possible to discern how technological progress provides some means not only for producing content but also for distributing it.

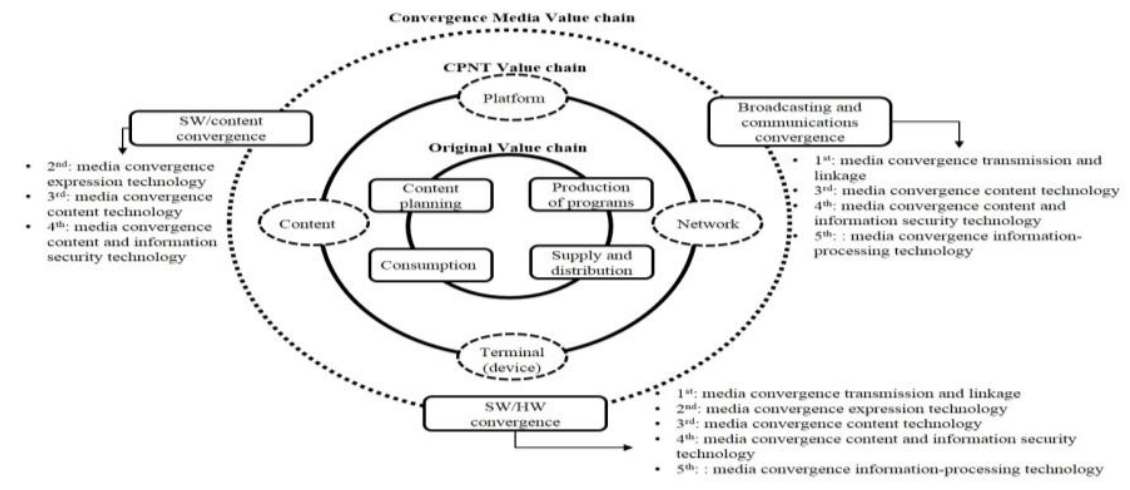

Figure 5. Convergent Ecosystem Value Chain Based on Broadcast and Communications Media Convergence 
In sum, in creative industries, technologies for service platforms and use can be the same, which has important implications for the conceptual shift in $R \& D$ activity. Unlike manufacturing-oriented industries, creative industries have to engage in technological $R \& D$ in conjunction with creative-content R\&D from the manufacturing stage, and therefore both tangible technological support and intangible R\&D activity exist in tandem, highlighting the need for policies supporting the creative activity of talented individuals. Technological progress facilitates economic growth, and the latter cannot happen without sufficient investment in people and content. In the end, it is important for the government to support timely technologies and nurture creative individuals who can lead future technologies to new economic value added.

\section{Acknowledgements}

This paper is a revised and expanded version of a paper entitled "The Analysis of the Media Convergence Ecosystem Value Chain" presented at NGCIT2014, Hochiminh (Vietnam), 24-26, Oct., 2014.

\section{References}

[1] S. W. Kim, "Building a Sustainable UX Ecosystem under N-Screen and Cloud Computing Paradigm," Journal of the Ergonomics Society of Korea, vol. 29, no. 4, (2010), pp. 553-561.

[2] H. N. Kim, "The Status and Prospect of Broadcasting \& Telecommunications Convergence Technology," KAIT Conference of Korea Association for ICT Promotion, Korea, (2010).

[3] J. Alic, "Technology in the Service Industries," International Journal of Technology Management, vol. 9, (1994), pp. 1-14.

[4] A. LiBerman, "The Entertainment Marketing Revolution", Bringing the Moguls, the Media and the Magic to the World, Published FT Press, (2002).

[5] S. I. Lee, "The IT New Business Strategy of the Communication Business Operator" Weekly Technology Trend vol. 1279, (2009), pp. 29-32, IITA, Korea.

[6] L. Kong, "Introduction: Culture, economy, policy: Trends and developments", Geoforum, vol. 31, (2000), pp. 385-390.

[7] P. Leo, "Creative restructuring of Singapore media: Research lacunas," Asia Pacific Media Educator, vol. 14, (2003), pp. 4-17.

[8] F. Vladica, "Understanding entertainment value: an investigation into the subjectivity of people who experience entertainment", Degree Theses of Ryerson University, (2012).

[9] S. Sayre and C. C. King, Entertainment and society: Audiences, trends, and impacts, London, England: Sage, (2003).

[10] J. Hartley, "Introduction in Creative industries", published Oxford, UK: Blackwell, (2005).

[11] J. M. Lee, et al., "Economic Impact of Culture Industries", Research by Korea Creative Contents Agency, Korea, (2007).

[12] D. Hesmondhalgh and A. Pratt, "Cultural industries and cultural policy," International Journal of Cultural Policy, vol. 11, no. 1, (2005), pp. 1-13.

[13] S. W. Kang and T. W. Hong, "Market Definition for New Telecommunications Services under Convergent Environment", ETRI, vol. 23, no. 2, (2008), Korea.

[14] DCMS, “Creative Industries Economic Estimates", Statistical Bulletin, London UK (2004)

[15] DCMS, "Evidence Toolkit-ET: Technical Report”, Statistical Bulletin, London UK (2004)

[16] DCMS, "Creative Industries Fact File", Statistical Bulletin, London UK (2002)

[17] DCMS, "Creative Industries Mapping Document", Statistical Bulletin, London UK (2001)

[18] J. Howkins, The Creative Economy: How People Make Money from Ideas, the Penguin Press, London: Allen Lane, (2001).

[19] S. K. Jung and H. L. Lim, "The Evolutions Research of the Broadcasting Communication Convergence and Media Industry", Korea Communications Commission, issue 2010-14, (2001).

[20] M. Dupagne and B. Garrison, "The meaning and influence of convergence: A qualitative case study of newsroom work at the Tampa News Center," Journalism Studies, vol. 7, no. 2, (2006), pp. 237-255.

[21] J. B. Ahn, et al., "The Broadcasting Communication Policy of Smart Media Age and the Future of Technology", Published of Jinhan MNB, Korea, (2012).

[22] ETRI, 2013 ETRI Technical Notice, Published ETRI Press, Korea, (2013). 
[23] H. Jenkins, Convergence Culture: Where Old and New Media Collide, New York University Press, New York, (2006).

[24] L. Jianhua, "Communication and the evolution of ecosystem," The Journal of Global Education, vol. 52, issue $1,(1998)$.

[25] "KDI, A Study on the Guideline of Preliminary Feasibility Study", in Published KDI, (2000), pp. 334-340.

[26] T. L. Saaty, "Decision Making for Leaders: The Analytic Hierarchy Process for Decisions in a Complex World", Analytic Hierarchy Process Series, RWS Publications, vol. 2, (2001).

\section{Authors}

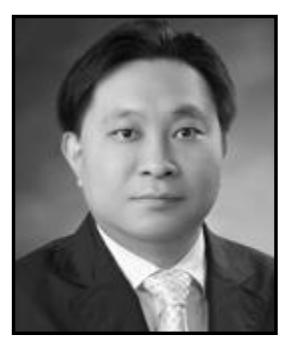

\section{Chi-Ung Song}

Research Fellow Science and Technology Policy Institute(STEPI)

The George Washington University, Washington DC USA

Ph.D. in Economics, September 1994-January 2005

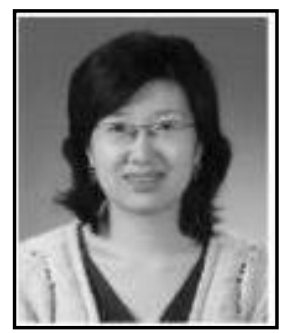

Mi-Young Park

Visiting Professor Seoul Women's University

Seoul Women's University, Seoul Korea

Ph.D. in Computer Engineering Science, March 2003-January 2009 